\title{
WOMEN'S WORK: THE INCLUSION OF THE VOICE OF ABORIGINAL WOMEN
}

\author{
LARISSA BEHRENDT*
}

Interesting issues arise around the intersection of including women's work in any law school curriculum and the experience of Aboriginal women. As an Aboriginal woman it seems a natural personal focus for me. The issues that the meeting of women's work and the experience of Aboriginal women raises are easily transferred through other areas of law.

The issue of work and Aboriginal women needs to be looked at in an historical context.

In stark contrast to non-Aboriginal, specifically European culture, Aboriginal women were not in a subordinate position to men. As in non-Aboriginal society, women were responsible for around 80 per cent of the provision of food. They were also the primary caretakers of the young, elderly and sick. Aboriginal women had their own culture and customs that men were not privy to. Female elders could be as powerful as male elders in their community. Most societies, including my own group, ${ }^{1}$ were matrilineal.

Post-invasion society has meant the permeation of one of the dominant culture's most repugnant values into our own community - sexism. And this dynamic has changed the social position of Aboriginal women within Australia. From being considered equal to men, we now occupy the lowest rung on the socioeconomic ladder.

The implication for this is that our work, our labour, has been devalued.

This devaluing of labour is a mirror to the way in which our culture has been devalued. And the natural consequence of this is that our socio-economic status has become entrenched in the lowest position of Australian society. Graphic evidence of the poverty of Aboriginal women comes from the analysis of statistics relating to the criminality of Aboriginal women.

Another difference between the experience of Aboriginal women and non-indigenous women ${ }^{2}$ is that in post-invasion society the Aboriginal woman within an Aboriginal family unit remained primarily responsible for the income of the family. It was often easier for Aboriginal women than Aboriginal men to find steady work as domestic servants putting Aboriginal women in the position of bread-winner that had long been denied non-Aboriginal women.

One issue that certainly needs to be considered is the impact of the Aborigines Protection Board. Every state in Australia had a version of this statutory authority which regulated the lives of Aboriginal people in a paternalistic and inhumane way.

There is much about the way that the Board's operations exploited the labour, and the sexuality of Aboriginal people, especially Aboriginal women. ${ }^{3}$ What I wish to focus on here is the policy of the removal of children. ${ }^{4}$

Under the policy of removal Aboriginal children were trained with the purpose of being a pool of cheap labour. Young Aboriginal boys trained as stockmen and Aboriginal women trained as domestic servants. The idea of training was farcical. My grandmother was removed under the policy and sent out to work for a white family in Parkes. She worked there for two years as a domestic servant. She was never paid for the work she did there. She was eventually sent to Sydney, when she fell pregnant to the man who owned the house in which she was used as slave labour.

This experience of the exploitation of child labour is an experience of many women sent to work as domestic servants. ${ }^{5}$ It is important to note that this is an experience similar to the experience of Aboriginal men removed by the state and subsequently used for labour. ${ }^{6}$ 
What is difficult about the integration of the issue of Aboriginal women's work into the curriculum is that it raises the issue of complicity of non-Aboriginal people, including non- Aboriginal women, in the oppression of women.

The challenge for us as teachers is to teach this without making students feel uncomfortable and therefore alienated to the extent that they tune out. Those students that have a genuine interest in issues of feminism and therefore those issues of Aboriginal women feel much more comfortable with hearing the bad stories of Aboriginal women being the victims of abuse by men, black and white. Students get more defensive when they no longer have the poor black sister picture presented to them.

The value in teaching this perspective is that it focuses the teaching of feminism on the hardest cases. Though I take the anti-essentialist view of Catharine MacKinnon's work. ${ }^{7}$ I think that she said something quite wise in her attempts to answer Angela Harris' criticism of her work. ${ }^{8}$ She said that if theory doesn't work for the black women it doesn't work at all. ${ }^{9}$

The focus of feminist teaching on the experiences of Aboriginal women is also valuable as it introduces the student to issues of intersectionality. Of race compounding with femaleness. Which can be compounded by sexual orientation. Which can be compounded by religious belief.

Theory and practice needs to acknowledge and accommodate the experiences of compounded "otherness". When white men ruled the areas of jurisprudence it was acceptable to them that the single perspective of while/male be used. Feminism has meant that theories are undermined or invalidated by the failure to take into account the experiences of women. As we allow access and voice to other previously excluded groups legal theories will need to be able to accommodate diverse perspectives and experience or withstand the ensuing criticism.

I have a vision of a world where a theory that does not ring true or allow space for the voices of "otherness" of "woman — colour — non-heterosexual — non-Christian” will not be a valid theory. All experiences will be seen as valid. Space will be given to the experience of all those now labelled as "other". Essentialists will be banished to the hinterlands of intellectual discourse.

Despite the challenges of accommodating different voices within legal debate, the beauty of its inclusion is that it acknowledges that everything is not black and white. It allows what we teach in the academy to be a reflection of the diversity of the society in which we live. And as important, it allows any member of a group that is considered "other" to find something within the curriculum that will connect to their point of view. It will give confidence to students, historically on the periphery of the classroom, confidence that their perspective is valid, valuable and important.

One of the problems with teaching the perspective of Aboriginal women is that there is very little material available as source materials. Our culture has an oral tradition so we do not have the volumes of works that European culture has. Past policies have ensured that Aboriginal children were not educated past the age of 14 effectively denying us a contribution to legal discourse in the accepted academic voice.

This is a problem that feminist scholars should have sympathy with. It is not unlike the experience of women being excluded from academic discourse and then having a different voice within the academy that is devalued.

Some interesting cultural conflicts occur with academia and our culture. Academia is much based on the written in contrast with our oral cultural tradition.

In our community experience is valued over study and academic discourse. In our communities it is elders who are respected for their opinion. Their wisdom comes from their lifetime of learning and experience. This is a very different approach to the access of knowledge through qualifications regardless of age.

An example of this cultural conflict is the experience of teaching an older Aboriginal woman: someone who traditionally would have passed knowledge to me. Teaching an older Aboriginal women of high standing in my community, for whom I have much personal respect and admiration, not only felt uncomfortable but it felt disrespectful.

Our culture is also very protective of a person's right to speak. Who speaks and who someone is speaking for are closely observed protocols. Academics' tendency to use other peoples' words and to use extracts with acknowledgment but often without seeking permission is an example of something that would never be done in our community without serious implications. 
There is also the problem that to an Aboriginal woman academic work seems like a luxury. I see women in my community working on life and death matters: getting food and medicine to families who do not have them. There is a luxury to theory in a war zone.

The problem for feminist teachers who wish to include the voice of Aboriginal women in their teaching is that for some of these reasons that I have briefly touched on, it is hard to find a source for Aboriginal women's experience. A void in academic discourse. The inclusion of voice is a core fight in the struggles of women in academia.

My suggestions are these:

- Value what we as Aboriginal women value.

- Include the voice of older Aboriginal women who are entitled to speak on the issues for which you seek to teach.

- Acknowledge the importance to us of oral culture and be prepared to include experience as much as theory.

My gut feeling is that feminists are not as resistant to alternative voices as conservative male (and female) counterparts. To achieve this, the challenge for the academy is in establishing links with the Aboriginal community to access Aboriginal women. This means approaching grass roots organisations. ${ }^{10}$ Acknowledging the sacrifice of time given by Aboriginal women, using more oral history and directing more resources towards the collating of oral history. This information must then be used in a respectful and appropriate way. ${ }^{11}$

Such perspectives are useful when integrated into introductory legal courses to introduce the existence of the perspective. The experience of Aboriginal women and their labour is useful in property courses to parallel the experience of non-Aboriginal women. There is also scope for materials to be used in Constitutional Law courses when looking at the way federal and state powers are used to regulate the lives of citizens and could be used in the curricula for human rights law.

Inclusion of the experience of Aboriginal women in relation to work, and indeed in relation to any other area of their experience will allow Aboriginal women a voice where they have been previously been silenced. A position that feminists themselves know all too well.

It is a concrete step towards offering Aboriginal women real support. Allow us a voice in feminist discourse, and a concrete step in improving the shaky relationship between Aboriginal women and the feminist movement will have been taken.

* Larissa Behrendt has been a Visiting Teaching Fellow at the University of New South Wales and has practiced as a solicitor in both private practice and for the Legal Aid Commission of NSW. She is currently enrolled in the doctoral program at Harvard Law School.

(C) 1996. (1995) 6 Legal Educ Rev 169.

1 I am a Eualeyai woman.

2 I take the point here that the experience of working class women is an important part of this dynamic and working class women were often in a position where they had to earn money for the family. The cultural expectations of European working class women is an interesting dynamic and their experience should be noted here.

3 There could be more research on the impact on the families of those who were removed, especially the impact on the mothers and fathers of the children that were stolen. The Aboriginal Medical Service in Redfern recently put together a video from its Mental Health Conference dealing with this.

4 The Protection Board was set up in 1909 in New South Wales. It had the power to remove children from their families from 1919 until 1969.

5 I recommend the film "Lousy Little Sixpence", and the books by R Sykes, Murawina: Australian Women of High Achievement (Sydney: Doubleday, 1993) and P. Read, The Stolen Generation, (Sydney: Ministry of Aboriginal Affairs, 1987) for further oral histories about the effect of the Board.

6 P Read, The Stolen Generation (Sydney: Ministry of Aboriginal Affairs, 1987) deals with the experiences of the men removed by the state as well.

7 See further, L Behrendt, Aboriginal Women and the White Lies of the Feminist Movement: Implications for Rights Discourse (1993) 1 Austl Feminist LJ 27

8 A Harris, Categorical Discourse and Dominance Theory (1989-90) 5 Berkeley Women's LJ 181.

9 C MacKinnon, From Practice to Theory or What is a White Woman Anyway? (1991) 4 Yale JL \& Feminism 13.

10 This is not easy. Outsiders need to be prepared for the suspicions of Aboriginal people about academics. Experiences with anthropologists have left many wary of people seeking information. There are also protocols and politics within the Aboriginal community that outsiders are not aware of. When establishing links, you need to find someone who is respected by the community who can guide you to appropriate people.

11 I am not advocating that oral history is the only way in which to include the voice of Aboriginal women in discourse. Eventually, I would hope that enough Aboriginal women are educated and able to contribute to debates in the formal academic way. Oral history acknowledges the real experience of Aboriginal women that has not been recorded and allows for an expression of experience in a 
way that is reflective of our culture at the same time. The ideal would be a marriage of written literature from the pens of Aboriginal women and words from the mouths of others. 